\title{
Testing longwave radiation parameterizations under clear and overcast skies at Storglaciären, Sweden
}

\author{
J. Sedlar ${ }^{1}$ and R. Hock ${ }^{2,3}$ \\ ${ }^{1}$ Department of Meteorology, Stockholm University, 10691 Stockholm, Sweden \\ ${ }^{2}$ Geophysical Institute, University of Alaska Fairbanks, AK 99775-7320, USA \\ ${ }^{3}$ Department of Earth Sciences, Uppsala University, 75236 Uppsala, Sweden
}

Received: 7 May 2008 - Published in The Cryosphere Discuss.: 1 July 2008

Revised: 9 April 2009 - Accepted: 9 April 2009 - Published: 27 April 2009

\begin{abstract}
Energy balance based glacier melt models require accurate estimates of incoming longwave radiation but direct measurements are often not available. Multi-year nearsurface meteorological data from Storglaciären, Northern Sweden, were used to evaluate commonly used longwave radiation parameterizations in a glacier environment under clear-sky and all-sky conditions. Parameterizations depending solely on air temperature performed worse than those which include water vapor pressure. All models tended to overestimate incoming longwave radiation during periods of low longwave radiation, while incoming longwave was underestimated when radiation was high. Under all-sky conditions root mean square error (RMSE) and mean bias error (MBE) were 17 to $20 \mathrm{~W} \mathrm{~m}^{-2}$ and -5 to $1 \mathrm{~W} \mathrm{~m}^{-2}$, respectively. Two attempts were made to circumvent the need of cloud cover data. First cloud fraction was parameterized as a function of the ratio, $\tau$, of measured incoming shortwave radiation and calculated top of atmosphere radiation. Second, $\tau$ was related directly to the cloud factor (i.e. the increase in sky emissivity due to clouds). Despite large scatter between $\tau$ and both cloud fraction and the cloud factor, resulting calculations of hourly incoming longwave radiation for both approaches were only slightly more variable with RMSE roughly $3 \mathrm{~W} \mathrm{~m}^{-2}$ larger compared to using cloud observations as input. This is promising for longwave radiation modeling in areas where shortwave radiation data are available but cloud observations are not.
\end{abstract}

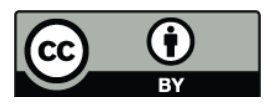

Correspondence to: J. Sedlar (josephs@misu.su.se)

\section{Introduction}

Energy balance studies on glaciers have shown that, on average, net radiation is usually the largest contributor to surface ice and snow melt (see summary in Hock, 2005). Examination of the individual radiative components reveals that incoming longwave radiation (also referred to as downward or downwelling longwave radiation) is by far the largest source of energy for melt, followed by absorbed shortwave (or global) radiation (Ohmura, 2001), which accounts for roughly a quarter of the total energy source for melt. Sensible heat flux normally provides the third largest energy source. The relative importance of incoming longwave radiation as a source of surface energy input, compared to shortwave radiation or turbulent heat fluxes, may vary as climate changes (Philipona et al., 2004), but it will remain a large contributor, especially in the higher latitudes, due to the seasonal dependence of shortwave radiation. Hence, its accurate modeling is of paramount importance in energy balance glacier melt modeling and assessing the response of glacier melt to climate warming.

Longwave radiative fluxes have generally received less attention than shortwave fluxes, partially due to difficulties and costs associated with accurate longwave radiation measurements, but also due to a void of measurable atmospheric parameters which longwave radiation is dependent upon, such as cloud cover (Aase and Idso, 1978; Müller, 1985; Marty and Philipona, 2000). Unlike shortwave radiation, incoming longwave radiation is not readily measured at automated weather stations, often being derived through combination of global and net radiation measurements or parameterizations, although the number of weather stations on glaciers equipped with longwave radiation instrumentation has increased during recent years (e.g. van den Broeke et al., 2004; Sicart et al., 2005, 2008; van de Wal et al., 2005; Hoch et al., 2007; Mölg et al., 2009).

Published by Copernicus Publications on behalf of the European Geosciences Union. 
The atmospheric flux of longwave radiation is emitted predominantly by clouds, water vapor, carbon dioxide and ozone. The flux varies mostly with the cloud amount and cloud optical depth, mean cloud emitting temperature, as well as integrated water vapor content (Marty et al., 2002). In mountainous areas longwave irradiance from the surrounding terrain may locally enhance irradiance and thus generate spatial variability in melt (Plüss and Ohmura, 1997; Sicart et al., 2006). Ideally, incident longwave radiative flux is modeled with physical models describing all emission and absorption processes in the atmosphere. However, such models are not applicable when vertical profile data of temperature and moisture are lacking. Hence, empirical relationships have been developed parameterizing incoming longwave radiation as a function of near-surface (e.g. 2-m screen-level) temperature and/or vapor pressure for clear-sky conditions, and in addition as a function of cloud fraction in the case of all-sky conditions. Use of standard meteorological measurements at near-surface level has proven sufficient since most incoming longwave radiation reaching the Earth's surface is emitted from the lowest layers of the troposphere (Ohmura, 2001). Only few studies have compared different parameterizations on the same data set (e.g. Sugitia and Brutsaert, 1993; Pirazzini et al., 2000; Gabathuler et al., 2001; Iziomon et al., 2003), and most studies have focused on lowland station data. Also, much attention has been devoted to clear-sky longwave radiation, although cloudy conditions often prevail in mountainous, glacier environments.

The purpose of this study is to evaluate various commonly used parameterizations of incoming longwave radiation in a glacier environment. The parameterizations vary in form, physical basis and number of independent variables, which include near-surface air temperature, water vapor pressure and cloud fraction. Further, we attempt to calculate incoming longwave radiation without observations of cloud fraction by two methods. First we develop a parameterization for cloud fraction since existing models often include it as independent variable, although such observations tend to be scarce in a glacier environment. Cloud fraction is parameterized as a function of the ratio of observed incoming shortwave radiation and computed top of atmosphere shortwave radiation, and this parameterization is incorporated into the calculations of longwave incoming radiation. Second we bypass the need for cloud data by parameterizing the cloud factor, i.e. the increase in sky emissivity due to clouds, as a function of the same ratio. Our analysis is based on a detailed micrometeorological data set collected on Storglaciären, a small glacier in Northern Sweden, spanning four melt seasons.

\section{Site description and data}

Storglaciären is located in Northern Sweden $\left(67^{\circ} 55^{\prime} \mathrm{N}\right.$, $18^{\circ} 35^{\prime} \mathrm{E}$ ) comprising an area of $\sim 3 \mathrm{~km}^{2}$. Elevation ranges between 1120-1730 ma.s.l. Mean summer temperature
(June-August, 1965-2003) at Tarfala Research Station located $\sim 1 \mathrm{~km}$ from the glacier is $-3.7^{\circ} \mathrm{C}$ (Radic and Hock, 2006). An automatic weather station was operated in the upper region of the ablation zone at approximately $1370 \mathrm{~m}$ a.s.l. during the 1998-2000 and 2002 melt seasons. A detailed description of measurements and instrumentation is found in Hock et al. (1999); important to this study are the observations of incoming longwave and shortwave radiation, nearsurface air temperature and humidity and cloud fraction.

An Eppley Precision Infrared Radiometer was used to measure incoming longwave radiation. The instrument underwent "Swiss modification" at the World Radiation Center in Davos, Switzerland, which incorporates three dome thermistors separated by $120^{\circ}$ and an elevation of $45^{\circ}$, rather than using a single thermistor as in the original instrument. Details are given in Philipona et al. (1995) who claim that the accuracy of the modified instrument is $2 \mathrm{~W} \mathrm{~m}^{-2}$ compared to approximately $10 \mathrm{~W} \mathrm{~m}^{-2}$ for the unmodified version. Shortwave radiation was measured by a Kipp \& Zonen CM11 with a reported maximum uncertainty of $2 \%$ for hourly values; temperature and humidity were measured using a Vaisala HMP45D. This instrument reports temperature accuracy of $\pm 0.3^{\circ} \mathrm{C}$ at $0^{\circ} \mathrm{C}$; humidity accuracy is reported as $\pm 3 \%(0<\mathrm{RH}<90 \%)$ and $\pm 4 \%(90<\mathrm{RH}<100 \%)$ at $0^{\circ} \mathrm{C}$. Temperature and humidity measurements were maintained at $2 \mathrm{~m}$ heights, while radiation measurements varied in height between $1-1.5 \mathrm{~m}$ above the glacier surface. All instruments mentioned above were artificially ventilated to reduce measurement errors. Measurements were logged once per minute from which hourly means were computed. The weather station was visited at least twice a week for most of the melt seasons. Manual sky observations were recorded by trained observers in the vicinity of the automatic weather station. Hourly cloud observations were performed, consisting of cloud fraction and cloud-base height categorized by three levels (high, middle, low).

\section{Methods}

\subsection{Incoming longwave radiation}

Incoming longwave radiation, $L \downarrow,\left(\mathrm{W} \mathrm{m}^{-2}\right)$ is generally expressed in terms of the Stefan-Boltzmann Law

$L \downarrow=\varepsilon_{\mathrm{eff}} \sigma T^{4}=\varepsilon_{c s} F \sigma T^{4}$

where $\varepsilon_{e f f}=\varepsilon_{c S} F$ is referred to as the effective or apparent emissivity (Unsworth and Monteith, 1975) and generally varies between roughly 0.7 for clear skies to close to unity for completely overcast skies; $\varepsilon_{c s}$ is the clear-sky atmospheric emissivity, $F$ (always $\geq 1$ ) is a cloud factor expressing the increase in $L \downarrow$ due to cloud emission compared to clear-sky conditions, $\sigma$ is the Stefan-Boltzmann constant $\left(5.67 \times 10^{-8} \mathrm{~W} \mathrm{~m}^{-2} \mathrm{~K}^{-4}\right)$ and $T$ is absolute temperature $(\mathrm{K})$ at the reference height (here $2 \mathrm{~m}$ ). Parameterizations 
of $\varepsilon_{c s}$ and $\varepsilon_{\text {eff }}$ have been developed both theoretically and empirically (e.g. Ångström, 1916; Brunt, 1932; Swinbank, 1963; Marshunova, 1966; Idso and Jackson, 1969; Maykut and Church, 1973; Brutsaert, 1975; Satterlund, 1979; Yamanouchi and Kawaguchi, 1984; Konzelmann et al., 1994; König-Langlo and Augstein, 1994), a number of which will comprise the suite of parameterizations that are tested on Storglaciären data in this paper.

\subsection{Emissivity parameterizations}

Seven parameterizations of clear-sky emissivity are analyzed (Table 1). The number and type of independent variables range from zero to two, allowing a model intercomparison dependent upon the number and type of independent variable(s) used. Parameterization coefficients $(a, b)$ are fitted to the Storglaciären data making a proper inter-model analysis possible. Clear-sky analysis is performed when observed cloud fraction $n \leq 1 / 8$, resulting in $318 \mathrm{~h}$ cases.

Three parameterizations for all-sky conditions are examined and listed in Table 2. The $\varepsilon_{\text {eff }}$ parameterizations from Bolz (1949) and König-Langlo and Augstein (1994) are principally different from Konzelmann et al. (1994). The former two parameterizations keep the clear-sky component regardless of cloud fraction while the latter reduces it as a cloud fraction increases. Coefficients are fitted to the data using all observed cloud fractions $(n=0-1, N=2332)$, except for the coefficient $a$ in the Konzelmann et al. (1994) parameterization; this coefficient corresponds to the overcast emissivity, $\varepsilon_{o c}$, and was fit to all hourly data with $n=1(N=1198)$. Fitted Konzelmann et al. (1994) parameterization coefficients lie within the range reported in the literature (Konzelmann et al., 1994; Greuell et al., 1997; Klok and Oerlemans, 2002). The three $\varepsilon_{\text {eff }}$ parameterizations and seven $\varepsilon_{c s}$ parameterizations are combined for $L \downarrow$ calculations according to Eq. (1).

\subsection{Parameterizing emissivity without cloud data}

Observations of cloud cover, though vital to $L \downarrow$ calculations, are often unavailable in high-latitude glacier environments. We explore the possibility of circumventing the need of cloud observations by including an atmospheric transmissivity in$\operatorname{dex}, \tau$, defined as the ratio of incoming shortwave radiation, $S \downarrow$, to theoretically calculated top of atmosphere shortwave radiation, $S \downarrow_{\text {toa }}$, dependent upon latitude, time of day and season

$\tau=\frac{S \downarrow}{S \downarrow_{\text {toa }}}$.

High values are indicative of clear-sky conditions while low values suggest overcast conditions. Some limitations to using Eq. (2) to simulate atmospheric transmissivity are discussed in Sect. 4.3. Since $\tau$ becomes less reliable as radiation amounts decrease, cases when solar zenith angle exceeded $80^{\circ}$ or $S \downarrow<15 \mathrm{~W} \mathrm{~m}^{-2}$ are excluded; also any cases when the measurement site was topographically shaded as determined from a digital elevation model and solar geometry are excluded.

First, we derive a parameterization for hourly and daily mean cloud fraction as a function of $\tau$ and substitute it for observed cloud fraction in the $\varepsilon_{\text {eff }}$ parameterizations given in Table 2. Sicart et al. (2006) apply a similar atmospheric transmissivity parameterization for data from a high-latitude mountainous region.

Second, the relationship between $F$ (Eq. 1) and $\tau$ is examined to explore the possibility to use $\tau$ directly without the intermediate step of computing a parameterized cloud fraction. We derive a parameterization for $F(\tau)$ for hourly and daily $L \downarrow$ calculations, thereby eliminating the need for cloud fraction data as independent variable.

$L \downarrow$ calculations based on $\varepsilon_{\text {eff }}$ parameterizations are compared with observations, and also compared to calculations using observed and parameterized cloud fraction. We use the root-mean square error (RMSE), an indication of the variability of a calculation about the observed value, and the mean bias error (MBE), a measure of the mean error for all calculations, to aid in identification of parameterization caveats.

\section{Results and Discussion}

\subsection{Clear-sky $L \downarrow$ calculations}

Clear-sky emissivities $\left(\varepsilon_{c s}=L \downarrow / \sigma T^{4}\right)$ obtained from all hourly data of $L \downarrow$ and $T$ from Storglaciären when cloud cover fraction $n \leq 1 / 8(N=205)$ tend to scatter around 0.7, generally consistent with clear-sky emissivities in prior studies (e.g. Konzelmann et al., 1994; Marty and Philipona, 2000). Statistics for clear-sky $L \downarrow$ calculations using the seven $\varepsilon_{c s}$ parameterizations are found in Table 1, indicating that all parameterizations show comparable performance. Correlation coefficients, $r$, and RMSE range from 0.84 to 0.88 , and 10 to $12 \mathrm{~W} \mathrm{~m}^{-2}$, respectively. Parameterizations that incorporate both $e$ and $T$, tend to have the smallest RMSE and MBE, except for the formulation by Marshunova (1966) which performs similarly well although it only includes vapor pressure as independent variable. The inclusion of atmospheric moisture leads to an improved parameterization performance, suggesting that vapor pressure has a larger relevance than temperature for parameterizing clear-sky $L \downarrow$. This reinforces the notion of water vapor being the most effective greenhouse gas. A scatter plot of calculated versus observed clear-sky longwave radiation is shown in Fig. 1 using the Konzelmann et al. (1994) parameterization as an example.

\subsection{All-sky $L \downarrow$ calculations}

Table 2 gives the correlation statistics for the three tested allsky emissivity parameterizations each adopting seven different clear-sky emissivity parameterizations. All combinations 
Table 1. Clear-sky emissivity, $\varepsilon_{c s}$, parameterizations ( $T$ is temperature $[\mathrm{K}], e$ is vapor pressure [Pa], both at screen-level) used in this study and coefficients $(a, b)$ fitted to the Storglaciären data set. Statistics result from comparing observations to calculations of clear-sky incoming longwave radiation applying the below parameterizations to Eq. (1). $r$ is correlation coefficient, RMSE is root-mean square error $\left(\mathrm{W} \mathrm{m}^{-2}\right)$ and MBE is mean bias error $\left(\mathrm{W} \mathrm{m}^{-2}\right)$.

\begin{tabular}{|c|c|c|c|c|}
\hline Clear-sky parameterization $\left(\varepsilon_{c s}\right)$ & Coefficients & $r$ & $\begin{array}{l}\text { RMSE } \\
\left(\mathrm{W} \mathrm{m}^{-2}\right)\end{array}$ & $\begin{array}{l}\mathrm{MBE} \\
\left(\mathrm{W} \mathrm{m}^{-2}\right)\end{array}$ \\
\hline $\begin{array}{l}\text { Maykut and Church (1973) } \\
\varepsilon_{c s}=a, \text { where } a=\text { constant }\end{array}$ & $a=0.7248$ & 0.85 & 10.9 & 0.1 \\
\hline $\begin{array}{l}\text { Marshunova (1966) } \\
\varepsilon_{c s}=a+b e_{a}^{1 / 2}\end{array}$ & $\begin{array}{l}a=0.5893 \\
b=5.351 \times 10^{-3}\end{array}$ & 0.88 & 9.6 & 0.1 \\
\hline $\begin{array}{l}\text { Swinbank (1963) } \\
\varepsilon_{c s}=a T^{b}\end{array}$ & $\begin{array}{l}a=9.294 \times 10^{-6} \\
b=2\end{array}$ & 0.85 & 11.9 & 0.2 \\
\hline $\begin{array}{l}\text { Idso and Jackson }(1969) \\
\varepsilon_{c s}=1-a\left(\exp \left[b(273-T)^{2}\right]\right)\end{array}$ & $\begin{array}{l}a=0.2811 \\
b=-3.523 \times 10^{-4}\end{array}$ & 0.84 & 10.8 & 0.0 \\
\hline $\begin{array}{l}\text { Brutsaert (1973) } \\
\varepsilon_{c s}=a(e / T)^{1 / b}\end{array}$ & $\begin{array}{l}a=0.6684 \\
b=10\end{array}$ & 0.88 & 9.5 & 0.3 \\
\hline $\begin{array}{l}\text { Satterlund (1979) } \\
\varepsilon_{c s}=a\left(1-\exp \left[-e^{T / 2016}\right]\right)\end{array}$ & $a=0.7396$ & 0.86 & 10.1 & 0.0 \\
\hline $\begin{array}{l}\text { Konzelmann et al. (1994) } \\
\varepsilon_{c s}=0.23+a(e / T)^{1 / b}\end{array}$ & $\begin{array}{l}a=0.4393 \\
b=7\end{array}$ & 0.88 & 9.5 & -0.2 \\
\hline
\end{tabular}

Table 2. Calculation statistics of hourly $L \downarrow$ for all-sky conditions computed from Eq. (1) using three effective emissivity, $\varepsilon_{\text {eff }}$, parameterizations and seven different clear-sky emissivity, $\varepsilon_{c s}$, parameterizations (left, with fitted coefficients). Fitted coefficients for $\varepsilon_{\text {eff }}$ parameterizations $(a, p)$ are found below the parameterizations. Statistics are the same as in Table 1; Var gives the independent variables $(T$ is temperature $[\mathrm{K}], e$ is vapor pressure [Pa]). Correlation coefficients, $r$, are listed once for each $\varepsilon_{c s}$ parameterization as they did not change by more than 0.01 for the three $\varepsilon_{\text {eff }}$ parameterizations.

\begin{tabular}{|c|c|c|c|c|c|c|c|c|}
\hline \multirow[b]{2}{*}{ Clear-sky parameterization $\left(\varepsilon_{c S}\right)$} & \multirow[b]{2}{*}{$\mathrm{V}$ ar } & \multirow[b]{2}{*}{$r$} & \multicolumn{2}{|c|}{$\begin{array}{c}\operatorname{Bolz}(1949) \\
\varepsilon_{\mathrm{eff}}=\varepsilon_{c s}\left(1+a n^{p}\right) \\
a=0.2959 \\
p=1.5\end{array}$} & \multicolumn{2}{|c|}{$\begin{array}{c}\text { König-Langlo and Augstein (1994) } \\
\qquad \begin{array}{c}\varepsilon_{\mathrm{eff}}=\varepsilon_{c s}+a n^{p} \\
a=0.2176 \\
p=1.5\end{array}\end{array}$} & \multicolumn{2}{|c|}{$\begin{array}{c}\text { Konzelmann et al. (1994) } \\
\varepsilon_{\text {eff }}=\varepsilon_{c s}\left(1-n^{p}\right)+a n^{p} \\
a=0.9552 \\
p=1.6\end{array}$} \\
\hline & & & $\begin{array}{l}\text { RMSE } \\
\left(\mathrm{W} \mathrm{m}^{-2}\right)\end{array}$ & $\begin{array}{r}\mathrm{MBE} \\
\left(\mathrm{W} \mathrm{m}^{-2}\right)\end{array}$ & $\begin{array}{l}\text { RMSE } \\
\left(\mathrm{W} \mathrm{m}^{-2}\right)\end{array}$ & $\begin{array}{r}\mathrm{MBE} \\
\left(\mathrm{W} \mathrm{m}^{-2}\right)\end{array}$ & $\begin{array}{l}\text { RMSE } \\
\left(\mathrm{W} \mathrm{m}^{-2}\right)\end{array}$ & $\begin{array}{l}\mathrm{MBE} \\
\left(\mathrm{W} \mathrm{m}^{-2}\right)\end{array}$ \\
\hline Maykut and Church (1973) & & & & & & & & \\
\hline $\begin{array}{l}\varepsilon_{c S}=0.7248 \\
\text { Marshunova (1966) }\end{array}$ & - & 0.87 & 18.1 & -3.1 & 18.0 & -2.3 & 17.8 & -0.2 \\
\hline $\begin{array}{l}\varepsilon_{c s}=0.5893+5.351 \times 10^{-3} e_{a}^{1 / 2} \\
\text { Swinbank (1963) }\end{array}$ & $e$ & 0.88 & 17.2 & 0.5 & 17.0 & 0.5 & 17.4 & 0.5 \\
\hline $\begin{array}{l}\varepsilon_{c s}=9.294 \times 10^{-6} T^{2} \\
\text { Idso and Jackson }(1969)\end{array}$ & $T$ & 0.85 & 20.0 & -4.7 & 19.2 & -3.6 & 17.8 & 0.2 \\
\hline $\begin{array}{l}\varepsilon_{c s}=1-0.2811\left(\exp \left[-3.523 \times 10^{-4}(273-T)^{2}\right]\right) \\
\text { Brutsaert }(1973)\end{array}$ & $T$ & 0.87 & 18.4 & -3.8 & 18.1 & -2.9 & 17.7 & 0.2 \\
\hline $\begin{array}{l}\varepsilon_{C s}=0.6684(e / T)^{1 / 10} \\
\text { Satterlund }(1979)\end{array}$ & $T, e$ & 0.89 & 17.1 & 1.0 & 17.0 & 0.9 & 17.4 & 0.6 \\
\hline $\begin{array}{l}\varepsilon_{c s}=0.7396\left(1-\exp \left[-e^{T / 2016}\right]\right) \\
\text { Konzelmann et al. }(1994)\end{array}$ & $T, e$ & 0.88 & 17.5 & -2.2 & 17.5 & -1.7 & 17.6 & 0.2 \\
\hline$\varepsilon_{c s}=0.23+0.4393(e / T)^{1 / 7}$ & $T, e$ & 0.89 & 17.0 & 0.3 & 16.9 & 0.3 & 17.4 & 0.4 \\
\hline
\end{tabular}

resulted in a similar range of $L \downarrow$ calculation statistics. RMSE varied between 17 and $20 \mathrm{~W} \mathrm{~m}^{-2}$, approximately 5.5 to $6.5 \%$ of mean measured $L \downarrow$, and MBE remained between -5 and $1 \mathrm{~W} \mathrm{~m}^{-2}$. All $\varepsilon_{\text {eff }}$ parameterizations performed best when the Konzelmann et al. (1994) $\varepsilon_{c s}$ parameterization was implemented. Besides calculations using the Konzelmann et al. (1994) $\varepsilon_{\text {eff }}$ parameterization, including near-surface vapor pressure as independent variable in $\varepsilon_{c s}$ parameterizations 


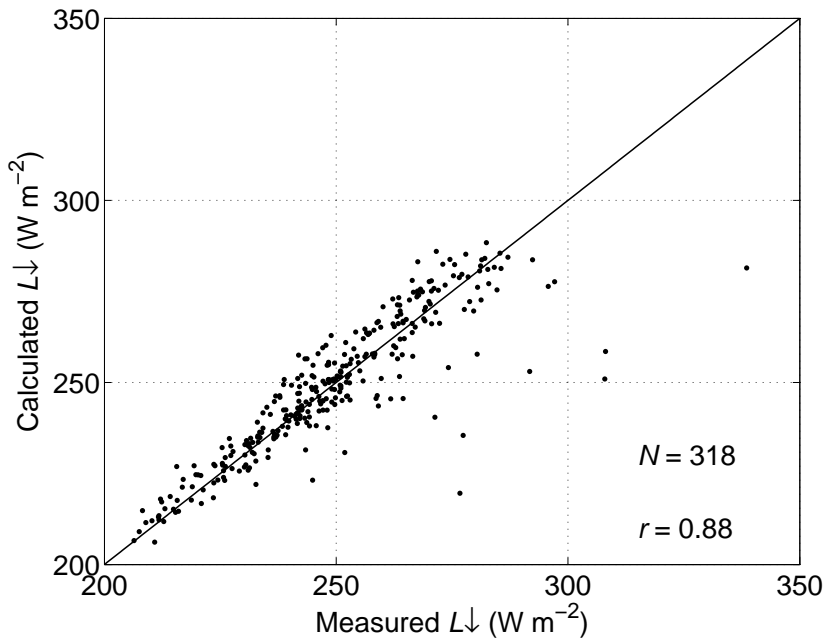

Fig. 1. Calculated versus measured hourly mean clear-sky $L \downarrow$, applying the clear-sky emissivity parameterization by Konzelmann et al. (1994). See Table 1 for parameterization details. $N$ is number of cases, $r$ is correlation coefficient.

results in a slight positive bias $\left(0\right.$ to $\left.1 \mathrm{~W} \mathrm{~m}^{-2}\right)$ whereas those parameterizations only including temperature reveal a larger negative bias of -2 to $-5 \mathrm{~W} \mathrm{~m}^{-2}$.

To further examine model performance, model error is related to measured longwave radiation (exemplified in Fig. 2a for one parameterization). Model error tends to be smallest during times of relatively small (clear-sky) and relatively large (overcast) observed radiation. Largest errors are found during partial cloudiness. Model error during partial cloudiness cannot entirely be attributed to shortcomings in the model. Manual sky observations are biased by the observer, and different cloud fractions can be a result of different cloud types (i.e. broken low-level stratiform clouds may give the same fraction as upper-level cirrus). Also, cloud optical depth and cloud phase (liquid, ice or mixed-phase) have significant influence over the efficiency of $L \downarrow$ emission (Curry et al., 1996; Garrett et al., 2002; Iacobellis et al., 2003; Inoue et al., 2006; Tjernström et al., 2008). Additionally, atmospheric optical depth is not constant, largely dependent upon water vapor and other atmospheric gases, aerosols, the surface albedo and perhaps even sub-visible clouds.

Figure $2 \mathrm{~b}$ shows the bin-averaged error as a function of observed $L \downarrow$ for all seven $\varepsilon_{c s}$ parameterizations applied to $\varepsilon_{\text {eff }}$ from König-Langlo and Augstein (1994). Systematic deviations are evident for all parameterizations. The general trend for all models is an overestimate of $L \downarrow$ when measured values are small and underestimated $L \downarrow$ when $L \downarrow$ is large. The models converge and trend towards an underestimation of $L \downarrow$ between 260 and $300 \mathrm{~W} \mathrm{~m}^{-2}$. Inter-model spread increases for smaller and larger values, although these should be examined cautiously as the number of observations per bin in those ranges is low (Fig. 2b). For observed values larger than $\sim 310 \mathrm{~W} \mathrm{~m}^{-2}$, the models deviate into two groups,

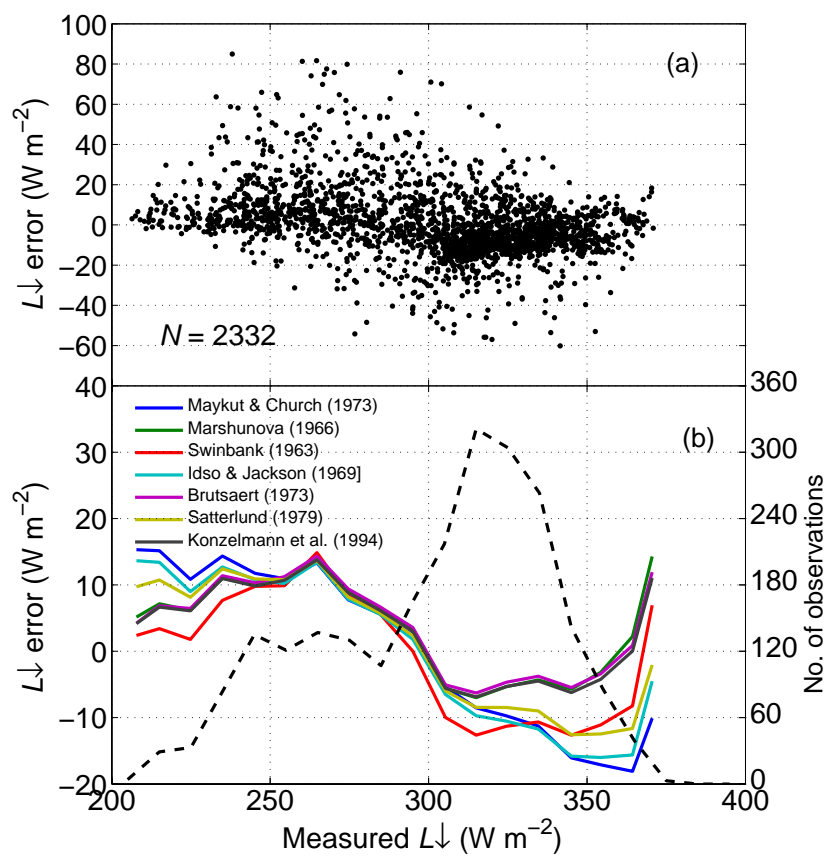

Fig. 2. Model error (modelled minus observed values) versus measured $L \downarrow$. (a) Hourly values applying the effective emissivity parameterization from König-Langlo and Augstein (1994) and the clear-sky parameterization from Konzelmann et al. (1994). (b) Mean hourly error averaged over ascending bins of $10 \mathrm{~W} \mathrm{~m}^{-2}$ calculated by applying seven clear-sky parameterizations from the literature to the effective emissivity parameterization from KönigLanglo and Augstein (1994). Dashed line (corresponding to y-axis on right) is the number of observations per bin.

one which has a bias of roughly $-5 \mathrm{~W} \mathrm{~m}^{-2}$ (for $L \downarrow$ between $\sim 310$ and $350 \mathrm{~W} \mathrm{~m}^{-2}$ ) and a second with a larger negative bias of roughly -10 to $-15 \mathrm{~W} \mathrm{~m}^{-2}$. The three models with smaller negative bias all contain vapor pressure in the $\varepsilon_{c s}$ parameterizations while (except for one parameterization) the ones with larger biases do not, suggesting that a measure of atmospheric moisture increases in importance as cloud fraction, and hence $L \downarrow$ flux, increases.

To assess the potential for coefficient universality, we adopt coefficients of the Konzelmann et al. (1994) parameterizations for $\varepsilon_{c s}$ and $\varepsilon_{\text {eff }}$ fitted to other glacier sites, and compare results to those obtained by fitting coefficients to our data set. We apply the coefficients obtained by Konzelmann et al. (1994) for a site in Greenland, those found by Klok and Oerlemans (2002) for Morteratschgletscher, Switzerland, and two sets of coefficients derived for two different sites on Pasterze, Austria (Greuell et al., 1997), and compute hourly all-sky $L \downarrow$ for the Storglaciären data set. RMSE, MBE and $r$ range from 19 to $20 \mathrm{~W} \mathrm{~m}^{-2},-2$ to $7 \mathrm{Wm}^{-2}$ and 0.85 to 0.87 , respectively. Although correlation statistics are broadly within similar ranges as those obtained from parameter fitting to the Storglaciären data set, results indicate that the relationship between measured and calculated $L \downarrow$ is strengthened using fitted coefficients. 


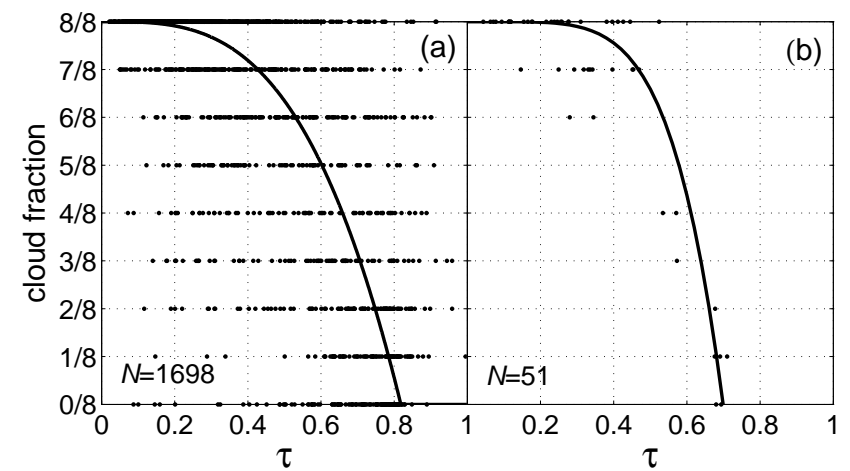

Fig. 3. Cloud fraction as a function of the ratio, $\tau$, of measured incoming shortwave radiation and top of atmosphere shortwave radiation for (a) hourly and (b) daily mean data. The lines are fitted non-linear parameterizations for cloud fraction $\left(n_{\text {param }}\right)$ as a function of $\tau$; the parameterization equation is found in Table $3 . N$ is the number of observations.

\subsection{Parameterizing cloud fraction}

The relationship between hourly cloud fraction and $\tau$ (Eq. 2) is shown in Fig. 3a. In general, $\tau$ increases as cloud fraction decreases, although the spread in $\tau$ for a specific cloud fraction is large. Much of this scatter is attributed to the difficulty in manual cloud observations, variation in cloud optical depth, cloud phase, surface albedo variation, aerosol scattering and absorption of incoming shortwave radiation $S \downarrow$ and variation of atmospheric optical depth. Variance of observed $L \downarrow$ for different cloud levels (high/mid/low, not shown) was found to be relatively small and of the same order of magnitude for the different levels, suggesting the vertical location of cloud base is not the primary source of scatter and uncertainty in using $\tau$.

A nonlinear cloud fraction parameterization of the form

$n_{\text {param }}(\tau)=\max \left\{a \tau^{b}+1 ; 0\right\}$

is developed and fit to observations in Fig. 3a, where $n_{\text {param }}$ is parameterized cloud fraction and $a$ and $b$ are coefficients that are fit to the data using a nonlinear, least squares fit. Equation (3) is substituted for observed cloud fraction $n$ in the $\varepsilon_{\text {eff }}$ parameterizations; we choose the $\varepsilon_{\text {eff }}$ parameterization by König-Langlo and Augstein (1994) as example. Coefficients to Eq. (3) and hourly calculation statistics using Eq. (3) are given in Table 3. Correlation coefficients are reduced, RMSE has increased by $\sim 3-4 \mathrm{~W} \mathrm{~m}^{-2}$ but MBE is still within the same range found when observed cloud fraction is used (Table 2). RMSE ranges roughly between $7-8 \%$ of the mean observed $L \downarrow$, the increase resulting from an inability of Eq. (3) to represent the observed variability in cloud fraction (Fig. 3). Calculation error as a function of measured $L \downarrow$ for hourly values is shown in Fig. 4a. Systematic $L \downarrow$ error is similar to that observed earlier when actual cloud fraction

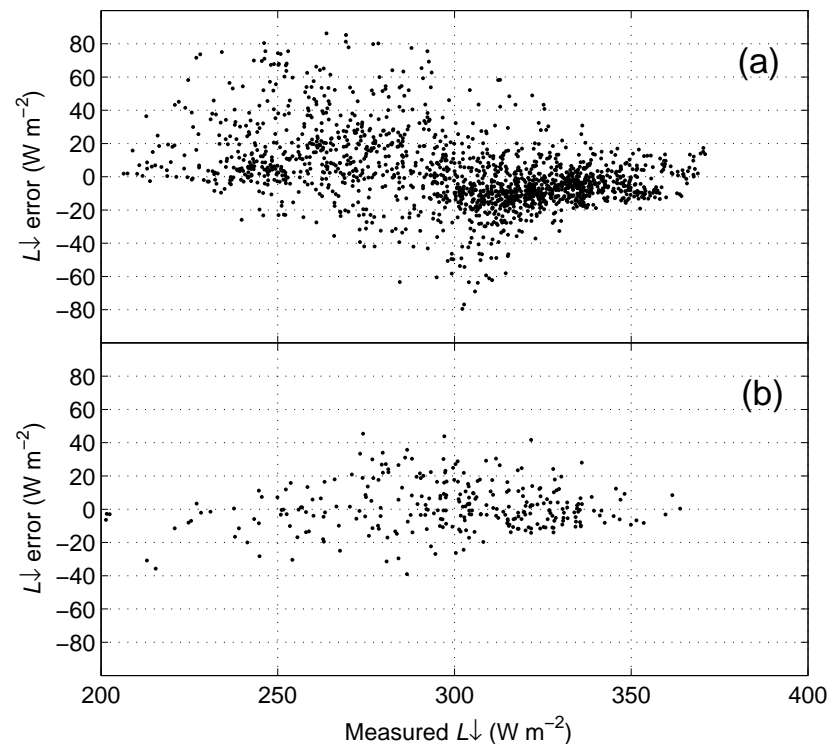

Fig. 4. (a) Hourly $(N=1698)$ and (b) daily $(N=292)$ error (modeled minus observed values) in $L \downarrow$ as a function of measured $L \downarrow$ applying parameterized cloud fraction in the effective emissivity parameterization by König-Langlo and Augstein (1994). Clear-sky emissivity is parameterized according to Konzelmann et al. (1994).

was used (Fig. 2a), although the absolute magnitude of errors during partial cloudiness tends to be larger.

This approach is also applied to daily mean data from Storglaciären because surface mass balance models often use daily means as input (e.g. Hock et al., 2007). Since cloud observations were not available throughout the night, daily mean cloud fraction was determined only for days $(N=51)$ where the observations indicated little to no change in cloud fraction over a 24-h period; the relationship between daily cloud fraction and $\tau$, including the fitted parameterization (Eq. 3) is shown in Fig. 3b. Coefficients and daily calculation statistics are presented in Table 3 showing larger correlation coefficients, reduced RMSE and MBE around zero. RMSE tends to be lowest for the parameterizations that do not have a measure of vapor pressure in the $\varepsilon_{c s}$ parameterization. The daily error plot (Fig. 4b) is scattered but the error tends to be centered around zero.

The use of $\tau$ to represent cloud fraction poses some complications, especially in glacier environments. Atmospheric transmissivity depends on variables other than cloud fraction, such as cloud and atmospheric optical depth and surface albedo. Fitzpatrick et al. (2004) emphasize the nonlinear relationship between surface albedo and cloud optical depth. When surface albedo is large, the incoming shortwave radiation flux is enhanced by multiple reflections between the surface and the cloud base. Hence, the relationship between $\tau$ and cloud fraction may vary in time as snow cover changes. Microphysical properties of clouds, along with the aerosol distribution, are known to alter cloud effectiveness 
Table 3. Calculation statistics of hourly and daily mean $L \downarrow$ using the König-Langlo and Augstein (1994) effective emissivity, $\varepsilon_{\text {eff }}$, parameterization, substituting parameterized cloud fraction $n_{\text {param }}$ for actual cloud fraction $n$, and seven different clear-sky emissivity, $\varepsilon_{c s}$, parameterizations. $T$ is temperature $[\mathrm{K}], e$ is vapor pressure $[\mathrm{Pa}]$.

\begin{tabular}{|c|c|c|c|c|c|c|}
\hline \multirow[b]{2}{*}{ Clear-sky parameterization $\left(\varepsilon_{c s}\right)$} & \multirow[b]{2}{*}{$r$} & \multicolumn{2}{|c|}{$\begin{array}{c}\text { Hourly Mean Data } \\
\text { König-Langlo and Augstein } \\
\text { (1994) } \\
\varepsilon_{\text {eff }}=\varepsilon_{c s}+a n_{\text {param }}^{b} \\
a=0.2176 \\
b=1.5 \\
n_{\text {param }}=-1.873 \tau^{3.249}+1\end{array}$} & \multirow[b]{2}{*}{$r$} & \multicolumn{2}{|c|}{$\begin{array}{c}\text { Daily Mean Data } \\
\text { König-Langlo and Augstein } \\
\text { (1994) } \\
\varepsilon_{\text {eff }}=\varepsilon_{c s}+a n_{\text {param }}^{b} \\
a=0.2176 \\
b=1.5 \\
n_{\text {param }}=-6.388 \tau^{5.178}+1\end{array}$} \\
\hline & & $\begin{array}{l}\text { RMSE } \\
\left(\mathrm{W} \mathrm{m}^{-2}\right)\end{array}$ & $\begin{array}{r}\mathrm{MBE} \\
\left(\mathrm{W} \mathrm{m}^{-2}\right)\end{array}$ & & $\begin{array}{l}\text { RMSE } \\
\left(\mathrm{W} \mathrm{m}^{-2}\right)\end{array}$ & $\begin{array}{r}\mathrm{MBE} \\
\left(\mathrm{W} \mathrm{m}^{-2}\right)\end{array}$ \\
\hline \multicolumn{7}{|l|}{ Maykut and Church (1973) } \\
\hline $\begin{array}{l}\varepsilon_{c s}=0.7248 \\
\text { Marshunova (1966) }\end{array}$ & 0.79 & 22.0 & -1.0 & 0.91 & 13.8 & 0.0 \\
\hline $\begin{array}{l}\varepsilon_{c s}=0.5893+5.351 \times 10^{-3} e_{a}^{1 / 2} \\
\text { Swinbank }(1963)\end{array}$ & 0.80 & 21.8 & 1.7 & 0.91 & 14.7 & 2.0 \\
\hline $\begin{array}{l}\varepsilon_{c s}=9.294 \times 10^{-6} T^{2} \\
\text { Idso and Jackson }(1969)\end{array}$ & 0.75 & 24.1 & -2.1 & 0.89 & 16.2 & -2.6 \\
\hline $\begin{array}{l}\varepsilon_{c s}=1-0.2811\left(\exp \left[-3.523 \times 10^{-4}(273-T)^{2}\right]\right) \\
\text { Brutsaert }(1973)\end{array}$ & 0.78 & 22.4 & -1.6 & 0.90 & 14.1 & -0.7 \\
\hline $\begin{array}{l}\varepsilon_{c s}=0.6684(e / T)^{1 / 10} \\
\text { Satterlund }(1979)\end{array}$ & 0.81 & 21.7 & 2.1 & 0.92 & 14.7 & 2.4 \\
\hline $\begin{array}{l}\varepsilon_{c s}=0.7396\left(1-\exp \left[-e^{T / 2016}\right]\right) \\
\text { Konzelmann et al. }(1994)\end{array}$ & 0.79 & 21.8 & -0.4 & 0.91 & 13.9 & 0.3 \\
\hline$\varepsilon_{C S}=0.23+0.4393(e / T)^{1 / 7}$ & 0.81 & 21.6 & 1.5 & 0.92 & 14.6 & 1.8 \\
\hline
\end{tabular}

in absorbing and emitting radiation, introducing additional uncertainties in using an atmospheric transmissivity index (Curry et al., 1996; Garrett et al., 2002; Iacobellis et al., 2003; Inoue et al., 2006; Tjernström et al., 2008). Another complication arises due to the geographical location of many glaciers. Often surrounded by terrain, during certain hours of the day this causes shading on the $S \downarrow$ sensor, which if not corrected for, will lead to falsely parameterized cloud fraction. Because we are using $S \downarrow$ observations, calculations using $\tau$ are limited to daylight hours, but this is often also the case when using manual cloud observations. Also, only melt season data has been analyzed. Higher latitudes in the Northern Hemisphere winter will be influenced by larger solar zenith angles, which may add bias to the relationship between cloud fraction and atmospheric transmissivity. This requires further investigation to assess the applicability of the cloud cover parameterization in other regions. Nevertheless, our results indicate that our simple cloud fraction parameterization performs surprisingly well considering its simple form and the large scatter between $\tau$ and cloud fraction.

\subsection{Cloud factor}

Rather than including a secondary cloud fraction parameterization within the $\varepsilon_{\text {eff }}$ parameterizations as performed above, we attempt to parameterize cloud factor $F$ as a function of atmospheric transmissivity $\tau$, directly. Figure 5 shows the relationship between $F=L \downarrow /\left(\varepsilon_{c S} \sigma T^{4}\right)$ and $\tau$ for hourly and daily observations. Scatter between $F$ and $\tau$ is considerable, but in general $F$ increases as $\tau$ decreases. The fitted parameterization equations are provided in the figure. Error plots (Fig. 6a-b) using the cloud factor parameterization (combined with $\varepsilon_{c s}$ parameterization from Konzelmann et al., 1994) are found to be similar to the models using observed cloud fraction (Fig. 2a) and the cloud fraction parameterization above (Fig. 4a-b). Hourly calculations result in $r=0.81$, $\mathrm{RMSE}=21.8 \mathrm{~W} \mathrm{~m}^{-2}$ and $\mathrm{MBE}=2.0 \mathrm{~W} \mathrm{~m}^{-2}$. Daily calculations show a strengthening in correlation between calculated and measured values with $r=0.92$, RMSE $=14.6 \mathrm{~W} \mathrm{~m}^{-2}$ and $\mathrm{MBE}=1.8 \mathrm{~W} \mathrm{~m}^{-2}$. These statistics are nearly identical to those obtained when cloud fraction was parameterized using the same atmospheric transmissivity index.

\section{Conclusions}

With coefficients fitted to the Storglaciären data set, all tested longwave radiation parameterizations differ only slightly in their performance when compared to hourly observations. RMSE for seven tested $\varepsilon_{c s}$ parameterizations range from 10 to $12 \mathrm{~W} \mathrm{~m}^{-2}$ under clear-sky conditions and from 17 to $20 \mathrm{~W} \mathrm{~m}^{-2}$ under all-sky conditions using three $\varepsilon_{\text {eff }}$ parameterizations, each combined with the seven $\varepsilon_{c s}$ parameterizations. Clear-sky cases are modelled most accurately, 


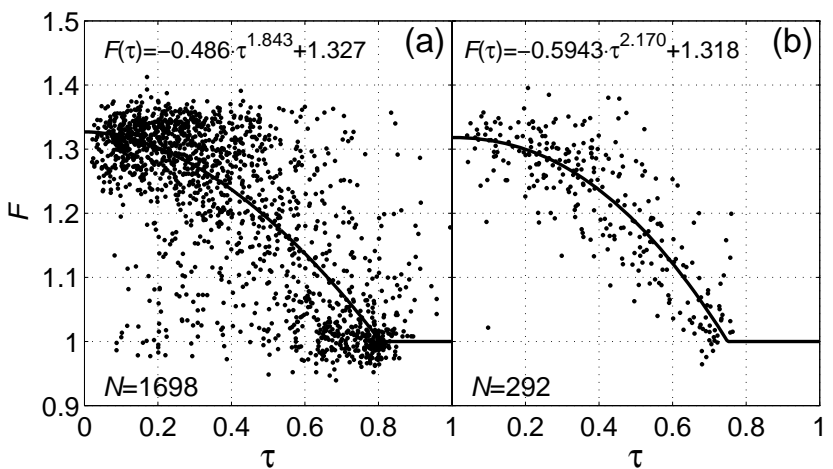

Fig. 5. Cloud factor $\left(F=L \downarrow /\left[\varepsilon_{c s} \sigma T^{4}\right]\right)$ as a function of $\tau$ (Eq. 3) for (a) hourly observations and (b) daily observations. The line represent the non-linear parameterization for $F(\tau)$ of the form provided near the top of each panel. Clear-sky emissivity is parameterized according to Konzelmann et al. (1994).

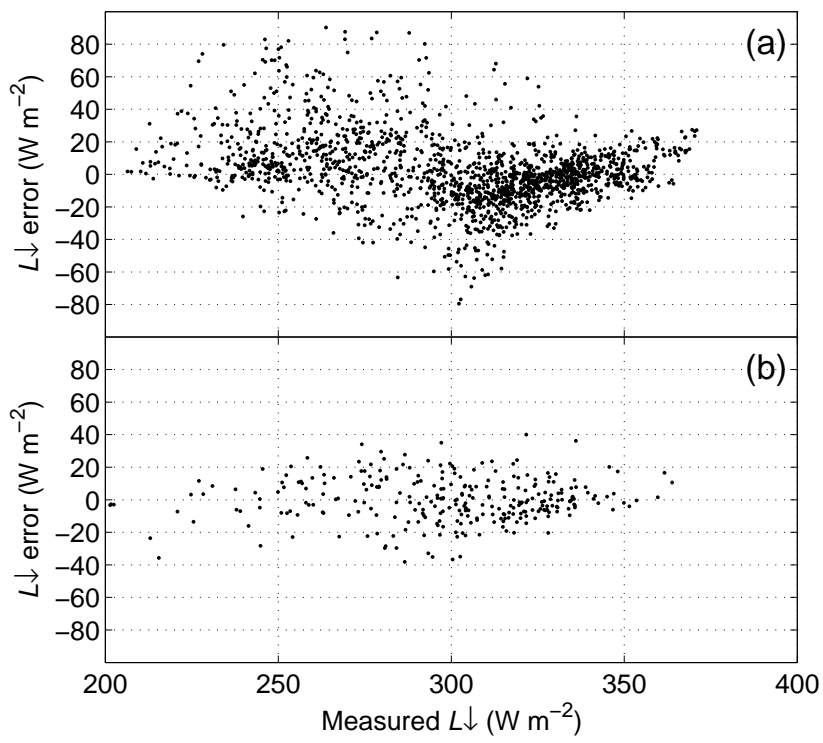

Fig. 6. Same as in Fig. 4, except $L \downarrow$ is calculated using Eq. (1) and applying cloud factor $F$ parameterized as a function of $\tau$ for (a) hourly $(N=1698)$ and $(\mathbf{b})$ daily mean $(N=292)$ data.

followed by overcast and finally partially cloudy skies, in agreement with Pirazzini et al. (2000). Clear-sky parameterizations that include near-surface vapor pressure tend to out-perform those consisting of only temperature, confirming that near-surface vapor pressure is an important variable due its impact as a greenhouse gas; near-surface temperature as independent variable should be applied in conjunction with vapor pressure. Systematic bias is evident across all models, where a tendency for overestimated $L \downarrow$ becomes an underestimate as measured $L \downarrow$ goes from small to large magnitudes.

Shortwave radiation is used to model cloud fraction by developing a nonlinear relationship between observed cloud fraction and an atmospheric transmissivity index, $\tau$, defined as the ratio of observed and calculated top-of-atmosphere shortwave radiation. When implemented into the $\varepsilon_{\text {eff }}$ parameterization by König-Langlo and Augstein (1994) combined with seven different $\varepsilon_{c s}$ parameterizations, RMSE varies between 22 and $24 \mathrm{~W} \mathrm{~m}^{-2}$ for hourly mean data, and 14 and $16 \mathrm{~W} \mathrm{~m}^{-2}$ for daily mean data, and thus is only slightly larger than for the calculations using observed cloud fraction; the range in MBE is comparable. Hence the cloud fraction parameterization performs surprisingly well despite its simple form and the large scatter between $\tau$ and cloud fraction. The drop in model performance compared to input of direct cloud observations is of similar magnitude to that when using the $\varepsilon_{\text {eff }}$ parameterization by Konzelmann et al. (1994) but adopting coefficients found at other glacier sites instead of those fitted to our data set.

To circumvent the intermediate step of computing a parameterized cloud fraction, which then is implemented into a $\varepsilon_{\text {eff }}$ parameterization, we parameterize the cloud factor $F$ directly as a function of atmospheric transmissivity. Correlation statistics are nearly identical to calculations made using the cloud fraction parameterization. Modelled longwave radiation fluxes show the same systematic error found when observed cloud fraction is applied to the all-sky $L \downarrow$ parameterizations tested here. Further development of cloud factor parameterizations dependent on shortwave radiation are promising but require further testing at other sites. Specifically, analyses of the dependence of $\tau$ on cloud and atmospheric optical depth, cloud microphysics and geometry, and surface albedo in mountainous glacier environments are required. Nevertheless, our results suggest that a simple nonlinear model including shortwave radiation can, sufficiently well, quantify the effects of cloud cover on $L \downarrow$ to be used in longwave radiation calculations.

Both approaches to circumvent the need of cloud fraction observations yield similar results when tested against the Storglaciären data set and perform only slightly worse when compared to use of cloud observations. This is promising for their use in locations where shortwave radiation measurements exist but cloud observations do not.

Acknowledgements. The authors would like to thank the two anonymous referees and scientific editor M. van den Broeke for their valuable feedback and suggestions.

Edited by: M. Van den Broeke

\section{References}

Aase, J. K. and Idso, S. B.: A Comparison of Two Formula Types for Calculating Long-Wave Radiation From the Atmosphere, Water Resour. Res., 14, 623-625, 1978.

Ångström, A.: Ÿber die Gegenstrahlung der Atmosphäre, Meteorol. Z., 33, 529-538, 1916.

Bolz, H. M.: Die Abhängigkeit der infraroten Gegenstrahlung von der Bewölkung, Meteorol. Z., 3, 201-203, 1949. 
Brunt, D.: Notes on radiation in the atmosphere, Q. J. Roy. Meteorol. Soc., 58, 389-418, 1932.

Brutsaert, W.: On a Derivable Formula for Long-Wave Radiation From Clear Skies, Water Resour. Res., 11, 742-744, 1975.

Curry, J. A., Rossow, W. B., Randall, D., and Schramm, J. L.: Overview of Arctic Cloud and Radiation Characteristics, J. Clim., 9, 1731-1764, 1996.

Fitzpatrick, M. F., Brandt, R. E., and Warren, S. G.:

Transmission of Solar Radiation by Clouds over Snow and Ice Surfaces: A Parameterization in Terms of Optical Depth, Solar Zenith Angle, and Surface Albedo, J. Climate, 17, 266-275, 2004.

Gabathuler, M., Marty, C., and Hanselmann, K. W.: Parameterization of incoming longwave radiation in high-mountain environments, Phys. Geogr., 22, 99-114, 2001.

Garrett, T. J., Radke, L. F., and Hobbs, P. V.: Aerosol Effects on Cloud Emissivity and Surface Longwave Heating in the Arctic, J. Atmos. Sci., 59, 769-778, 2002.

Greuell, W., Knap, W. H., and Smeets, P. C.: Elevational changes in meteorological variables along a midlatitude glacier during summer, J. Geophys. Res.-Atmos., 102(D22), 25 941-25 954, 1997.

Hoch, S. W., Calanca, P., Philipona, R., and Ohmura, A.: Yearround observation of longwave radiative flux divergence in Greenland, J. Appl. Meteorol. Clim., 46(9), 1469-1479, 2007.

Hock, R., Carrivick, J. L., and Jonsell, U.: Glacio-Meteorological Studies On Storglaciären In 1999, Tarfala Research Station - Annual Report 1998-99, Department of Physical Geography, Stockholm University, 20-23, 1999.

Hock, R.: Glacier melt: A review on processes and their modelling, Prog. Phys. Geog., 29(3), 362-391, 2005.

Hock R., Radić, V., and de Woul, M.: Climate sensitivity of Storglaciären - An intercomparison of mass balance models using ERA-40 reanalysis and regional climate model data, Ann. Glaciol. 46, 342-348, 2007.

Iacobellis, S. F., McFarquhar, G. M., Mitchell, D. L., and Somerville, R. C. J.: The Sensitiviy of Radiative Fluxes to Parameterized Cloud Microphysics, J. Clim., 16, 2979-2996, 2003.

Idso, S. B. and Jackson, R. D.: Thermal radiation from the atmosphere, J. Geophys. Res., 74, 5397-5403, 1969.

Inoue, J., Liu, J., Pinto, J. O., and Curry, J. A.: Intercomparison of Arctic Regional Climate Models: Modeling Clouds and Radiation for SHEBA in May 1998, J. Climate, 19, 4167-4178, 2006.

Iziomon, M. G., Mayer, H., and Matzarakis, A.: Downward atmospheric longwave irradiance under clear and cloudy skies: Measurement and parameterization, J. Atmos. Sol-Terr. Phy., 65, 1107-1116, 2003.

Klok, E. J. and Oerlemans, J.: Model study of the spatial distribution of the energy and mass balance of Morteratschgletscher, Switzerland, J. Glaciol., 505-518, 2002.

König-Lango, G. and Augstein, F.: Parameterization of the downward long-wave radiation at the Earths surface in polar regions, Meteorol. Z., 3, 343-347, 1994.

Konzelmann, T., van de Wal, R. S. W., Greuell, W., Bintanja, R., Henneken, E. A. C., and Abe-Ouchi, A.: Parameterization of global and longwave incoming radiation for the Greenland Ice Sheet, Global Planet. Change, 9, 143-164, 1994.

Marshunova, M. S.: Principal Characteristics of the radiation balance of the underlying surface, in: Soviet Data on the Arctic Heat Budget and Its Climate Influence, edited by: Fletcher, J. O.,
Keller, B., and Olenicoff, S. M., Rand Corp., Santa Monica, CA, Rep. R.M. 5003-PR, 1966.

Marty, C. and Philipona, R.: The Clear-Sky Index to separate ClearSky from Cloudy-Sky Situations in Climate Research, J. Geophys. Res., 27, 2649-2652, 2000.

Marty, C., Philipona, R., Fröhlich, C., and Ohmura, A.: Altitude dependence of surface radiation fluxes and cloud forcing in the Alps: Results from the alpine surface budget network, Theor. Appl. Climatol., 72, 137-155, 2002.

Maykut, G. A. and Church, P. E.: Radiation Climate of Barrow, Alaska, 1962-1966, J. Appl. Meteorol., 12, 620-628, 1973.

Mölg, T., Cullen, N. J., and Kaser, G.: Solar radiation, cloudiness and longwave radiation over low-latitude glaciers: Implications for mass balance modelling, J. Glaciol., 55(190), 292-302, 2009.

Müller, H.: Review paper: On the radiation budget in the Alps, J. Climatol., 5, 445-462, 1985.

Ohmura, A.: Physical Basis for the Temperature-Based Melt-Index Model, J. Appl. Meteorol., 753-761, 2001.

Philipona, R., Fröhlich, C., and Betz, C.: Characterization of pyrgeometers and the accuracy of atmospheric long-wave radiation measurements, Appl. Optics, 34, 1598-1605, 1995.

Philipona, R., Dürr, B., Marty, C., Ohmura, A., and Wild, M.: Radiative forcing - measured at Earth's surface - corroborate the increasing greenhouse effect, J. Geophys. Res., 31(N3), L03202, $1-4,2004$.

Pirazzini, R., Nardino, M., Orsini, A., Calzolari, F., Georgiadis, T., and Levizzani, V.: Parameterization of the downward longwave radiation from clear and cloudy skies at Ny Ålesund (Svalbard), /IRS 2000: Current Problems in Atmospheric Radiation, edited by: Smith, W. L. and Timofeyev, Y. M., A. Deepack Publishing, Hampton, Virginia, 559-562, 2000.

Plüss, C. and Ohmura, A.: Longwave Radiation on Snow-Covered Mountainous Surfaces, J. Appl. Meteorol., 36, 818-824, 1997.

Radic, V. and Hock, R.: Modeling future glacier mass balance and volume changes using ERA-40 reanalysis and climate models: A sensitivity study at Storglaciären, Sweden, J. Geophys. Res., 111, F03003, doi:10.1029/2005JF000440, 2006.

Satterlund, D. R.: An improved equation for estimating longwave radiation from the atmosphere, Water Resour. Res., 15(6), 16491650, 1979.

Sicart, J. E., Wagnon, P., and Ribstein, P.: Atmospheric controls of the heat balance of Zongo Glacier ( $16^{\circ} \mathrm{S}$, Bolivia), J. Geophys. Res., 110, D12106, doi:10.1029/2004JD005732, 2005.

Sicart, J. E., Pomeroy, J. W., Essery, R. L. H., and Bewley, D.: Incoming longwave radiation to melting snow: observations, sensitivity and estimation in northern environments, Hydrol. Process., 20, 3697-3708, 2006.

Sicart, J. E., Hock, R., and Six, D.: Glacier melt, air temperature, and energy balance in different climates: The Bolivian Tropics, the French Alps, and Northern Sweden, J. Geophys. Res., 113, D24113, doi:10.1029/2008JD010406, 2008.

Sugita, M. and Brutsaert, W.: Cloud Effect in the Estimation of Instantaneous Downward Longwave Radiation, Water Resour. Res., 29, 599-605, 1993.

Swinbank, W. C.: Long-wave radiation from clear skies, Q. J. Roy. Meteorol. Soc., 89, 330-348, 1963.

Tjernström, M., Sedlar, J., and Shupe, M. D.: How Well Do Regional Climate Models Reproduce Radiation and Clouds in the Arctic?, An Evaluation of ARCMIP Simulations, 
J. Appl. Meteorol. Clim., 47, 2405-2422, 2008.

Unsworth, M. H. and Monteith, J. L.: Geometry of long-wave radiation at the ground. I. Angular distribution of incoming radiation, Q. J. Roy. Meteorol. Soc., 101, 13-24, 1975.

van den Broeke, M. R., Reijmer, C. H., and van de Wal, R. S. W.:

The surface radiation balance in Antarctica as measured with Automatic Weather Stations, J. Geophys. Res., 109, 1-16, 2004. van de Wal, R. S. W., Greuell, W., van den Broeke, M. R., Reijmer, C. J., and Oerlemans, J.: Surface mass-balance observations and automatic weather station data along a transect near Kangerlussuaq, West Greenland, Ann. Glaciol., 42, 311-316, 2005.

Yamanouchi, T. and Kawaguchi, S.: Longwave radiation balance under a strong surface inversion in the katabatic wind zone, Antarctica, J. Geophys. Res., 89(D7), 11 771-11 778, 1984. 